\title{
CORRESPONDENCE
}

\author{
78 WOOdCREST ROAD, \\ Purley, \\ SURREY.
}

$3, d$ March 1966

The Editor, T. F. A.

Dear Sir,

\section{CIGARETTE SMOKING AND EXTRA MORTALITY}

Recently I have been doing a few "back of an envelope" calculations on the extra mortality among cigarette smokers in England and Wales; the results I find very disturbing.

Starting from the lung cancer deaths, American research indicates that these form only one sixth of the extra desths among cigarette smokers. If we call this one fifth and say that about 80 per cent of the observed lung cancer deaths occur amongst cigarette smokers, then the total annual extra deaths among cigarette smokers in England and Wales amount to 100,000 or about 18 per cent of all deaths.

Or again, starting from the statement by the Chief Medical Officer of the Ministry of Health that the death rate of male cigarette smokers is twice that of non-smokers below age 65 , an estimate can be made of the extra deaths from the population statistics in quinquennial age groups separated for sex. Let us assume that 70 per cent of adult males and 20 per cent of adult females are cigarette smokers. The annual consumption of cigarettes in England and Wales is about 100,000 million, so that these assumptions produce a daily average of just under 20 cigarettes smoked, which appears to be reasonahle but, if anything, underestimates the number of habitual smokers. These assumptions produce extra deaths of about 47,500 (38,000 males and 9,500 females) between 20 and 65 . The next decennial group of ages is not so easy to assess. American experience suggests an extra deaths ratio of about 60-70 per cent giving the number of extra deaths as about 32,000 (25,000 males, 7,000 females). Thus there would be an annual amount of extra deaths of about 80,000 amongst cigarette smokers between 20 and 75. These figures are "extra" in the sense that, if one could replace the population of England and Wales by an exactly similar one none of whom had ever smoked a cigarette, one would expect the number of deaths in the next year to drop by the "extra" number.

I consider that the figures arrived at from both estimates are reasonably in accord and $I$ therefore wonder whether the authorities have not taken far too complacent a view about the effects of cigarette smoking; on these figures it is a menace many times more serious than road accidents. 
One feature specially worthy of notice is the great difference in the number of extra deaths botween males and females. Does the greater prevalence of cigarette smoking among males explain the failure of male mortality to improve as rapidly as female mortality has done in recent years?

\section{Yours faithfully,}

A. C. STALKER 